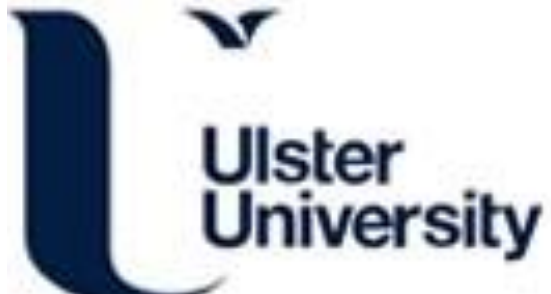

\section{Standards in regulating quality of adult community health and social care: systematic narrative review}

Cunningham, S., Taylor, B., \& Murphy, A. (2020). Standards in regulating quality of adult community health and social care: systematic narrative review. Journal of Evidence-Based Social Work, 17(4), 457-468.

https://doi.org/10.1080/26408066.2020.1770647

Link to publication record in Ulster University Research Portal

Published in:

Journal of Evidence-Based Social Work

Publication Status:

Published (in print/issue): 03/07/2020

DOI:

10.1080/26408066.2020.1770647

\section{Document Version}

Author Accepted version

\section{General rights}

Copyright for the publications made accessible via Ulster University's Research Portal is retained by the author(s) and / or other copyright owners and it is a condition of accessing these publications that users recognise and abide by the legal requirements associated with these rights.

\section{Take down policy}

The Research Portal is Ulster University's institutional repository that provides access to Ulster's research outputs. Every effort has been made to ensure that content in the Research Portal does not infringe any person's rights, or applicable UK laws. If you discover content in the Research Portal that you believe breaches copyright or violates any law, please contact pure-support@ulster.ac.uk. 


\title{
Standards in regulating quality of adult community health and social care: systematic narrative review
}

\section{Suzanne Cunningham}

Inspector, Regulation and Quality Improvement Authority, Belfast, Northern Ireland

\section{Brian J Taylor}

Professor of Social Work, Ulster University, Belfast, Northern Ireland

ORCID: orcid.org/0000-0002-3833-1986

\section{Audrey Murphy}

Assistant Director, Regulation and Quality Improvement Authority, Belfast, Northern Ireland

\author{
CORRESPONDING AUTHOR: \\ Brian J Taylor \\ Professor of Social Work, \\ Ulster University, Belfast, Northern Ireland \\ bj.taylor@ulster.ac.uk
}

CITE AS: Cunningham S, Taylor BJ \& Murphy A (2020) Standards in regulating adult health and social care establishments in the community: systematic narrative review. Journal of Evidence-based Social Work, 17(4), 457-468.

http://dx.doi.org/10.1080/26408066.2020.1770647 [submitted 17jan20; accepted 13 May 2020; doi issued 15 May 2020; published online 05 June 2020]

\section{Abstract}

Purpose: The growing range and complexity of community care services requires robust approaches to ensuring quality. Method: This review collated studies on the use of standards in regulating community health and social care using Social Care Online, Medline and CINAHL databases. Studies were appraised by two reviewers, and synthesised by study themes. Results: Sixteen studies were synthesised under three themes:

- standards in quality assurance and quality improvement;

- effectiveness of standards; and

- design of regulatory standards.

Standards facilitate providers in self-regulation, and enable regulators to support and monitor improvement. Effectiveness of standards depends on their language and interpretation, and on organisational factors. There was little evidence of scales within quality standards. Discussion: There is continuing debate about self-regulation versus external regulation. Social care service regulation requires more research. Conclusion: Regulatory organisations should take note of wider initiatives towards evidence-based practice in the design of quality standards.

\section{Keywords}

Benchmarking; quality improvement; review, literature; standards of care.

As identified health and social care needs become more specialised, and treatments and interventions more sophisticated, services become more complex. There are increasing challenges in designing appropriate processes to ensure the safety and quality of the developing health and social care systems. The focus of this review is on the use of standards to ensure and improve the quality of adult health and social care services in the community.

To illustrate the range and complexity of community health and social care services for adults to be regulated in a modern welfare system, the Regulation and Quality Improvement Authority for Northern Ireland (RQIA) (where the authors work) serves a population of about 
two million people, and regulates (at 01 June 2020) the following adult community health and social care services:

- about 250 Nursing Homes;

- about 225 Residential Care Homes;

- about 200 Day Care Centres and Day Support Schemes;

- about 300 Domiciliary Care Schemes;

- about 50 Independent Nursing Agencies; and

- 4 Adult Placement Agencies.

As an illustration of the anticipated growth of adult health and social care services, the Australian Aged Care Financing Authority reported in 2013 that an additional 74,000 residential aged care beds would be required over the next decade for their population of 25 million (Baldwin et al., 2015). Similar challenges pertain across Europe and North America (Harris, 2016; Simmons et al., 2012), and elsewhere.

Using measures of performance to ensure quality and safety may prompt service improvement responses or may generate an attitude of seeking to attain only what is minimally acceptable. Standards are used frequently by regulatory (licensing) authorities to benchmark minimum standards of care, although regulatory arrangements vary (Baldwin et al., 2015; Care and Social Services Inspectorate in Wales, 2016; Care Inspectorate, 2016; Care Quality Commission, 2016; Care Quality Commission, 2017; Office of Health Care Quality Maryland, 2019; Regulation and Quality Improvement Authority, 2016). Such standards may be used to detect problems; to inform the public; to persuade or require improvement by service providers; and to fulfil statutory requirements by regulators.

The development of regulation in social care presents particular challenges in regulating a diversity of small providers spanning a wide range of services, including day care and home care services as well as residential institutions (Fleming \& Taylor, 2010; Taylor \& Donnelly, 2006). In some jurisdictions, the management and regulation of social care services is becoming increasingly integrated with management and regulation of community health care services as services respond to the changing population profile; the increase in chronic conditions; and acknowledgement of the benefits of more closely integrated services (Taylor, 1998, 1999; 2012a). This developing integration provides opportunities for mutual learning across health and social care services.

This review of the use of standards in regulation was written in the context of Northern Ireland, where the statutory framework for regulation spans both health and social care (Health and Personal Social Services (Quality, Improvement and Regulation) (Northern Ireland) Order 2003). This is supported by an integrated clinical and social care governance framework (Taylor \& Campbell, 2011); a social work research and continuous improvement strategy (Health and Social Care Board, 2015); and a social work strategy which directs social workers to focus more strongly on measuring and evaluating improvements in social care services and the difference made in the lives of those receiving services (Health and Social Care Board, 2012).

The regulation of community health and social care services raises complex risk issues (Taylor, 2006, 2017a). The media is often quick to allocate blame, making reasonable, proportionate regulation more difficult (Killick \& Taylor, 2020; Resodihardjo, 2020; Taylor, 2017b). National politics, economic realities, culture and policies for health and social care may influence the approach to use of care standards (Scheweppenstedde et al., 2014).

This review focuses on how standards (benchmarks) and quality measures are used to regulate adult community health and social care services. A preliminary scoping review indicated that there are too few published studies on the use of standards in regulating social care services to merit a review focusing on these alone.

\section{Data sources}

Three bibliographic databases were searched: Social Care Online, Medline (OVID), and CINAHL. Truncation was used to retrieve variations such as plurals and case endings (Taylor 
et al., 2015). The Cochrane and Campbell Collaboration Libraries were searched for relevant reviews to avoid duplication This identified one related review (Flodgren et al., 2011) although this did not focus on the use of standards within regulation. The database searching was augmented by citation searching (references in all included studies) and by references supplied by colleagues working in the field.

\section{Study selection}

The literature search was developed in consultation with a specialist University librarian, using the basic approach of the Cochrane Collaboration extended into social care literature (Best et al., 2014; Campbell et al., 2018; Mc Elhinney et al., 2016; McFadden et al., 2012; McGinn et al., 2016; Stevenson et al., 2016; Taylor et al., 2003, 2007). The overall search structure involved the concept groups:

- <types of adult health and social care services that are regulated in the community, including: residential care, nursing homes, day care establishments, and home care services>

- AND

- <regulatory processes and methods: including international terms such as licensure, benchmarking, quality, and accreditation>

- AND

- <adults $>$.

Experimentation showed that inclusion of the final concept group increased search precision (ie. avoiding retrieving so many irrelevant items) whilst not reducing sensitivity (ie. ability to retrieve relevant studies). The terminology was informed by a Cochrane Review and Protocol on related topics (Flodgren et al., 2011; Brennan et al., 2017).

The inclusion criteria were:

- $\quad$ published 01 January 2006 to 31 December 2016;

- full text available in English;

- $\quad$ empirical research of any design; and

- $\quad$ adult health and social care in the community including day care, nursing homes, and residential care but excluding children's services, community hospitals and studies relating to specific medical procedures.

Study identification is illustrated in Table 1.

Table 1. Study identification.

\begin{tabular}{|l|l|l|l|l|}
\hline Source & $\begin{array}{l}\text { Date of final } \\
\text { search }\end{array}$ & $\begin{array}{l}\text { Hits from } \\
\text { search }\end{array}$ & $\begin{array}{l}\text { Initial selection } \\
\text { based } \\
\text { abstract }\end{array}$ & $\begin{array}{l}\text { Selected for } \\
\text { synthesis }\end{array}$ \\
\hline Medline (Ovid) & $15 / 01 / 2017$ & 2,473 & 61 & 14 \\
\hline CINAHL Care & $15 / 01 / 2017$ & 2,335 & 29 & 5 \\
\hline $\begin{array}{l}\text { Social } \\
\text { Online }\end{array}$ & $15 / 01 / 2017$ & 286 & 9 & 2 \\
\hline $\begin{array}{l}\text { Expert } \\
\text { recommendation }\end{array}$ & $31 / 01 / 2017$ & 6 & 2 & 2 \\
\hline
\end{tabular}

Note. the final column includes duplicates across databases

The quality criteria for inclusion were that studies were empirical research and were published in a peer-reviewed journal. Quality appraisal tools for surveys (QAT-S) and qualitative studies (QAT-Q) (Taylor et al., 2015) were used as appropriate to appraise quality. The most relevant quality characteristics are highlighted within the synthesis.

\section{Data extraction}

Sixteen studies were identified in peer-reviewed journals. Data were extracted using a table identifying location, study design, sample, data collection method and main findings. 


\section{Results of data synthesis}

The sixteen studies reviewed included eight cross-sectional surveys, five qualitative and three mixed methods studies (Taylor \& Moorhead, 2020). Data collection methods included use of review and audit data produced by regulators, questionnaires, field observations and interviews. Five studies were of residential care of older people; one of residential care for people with disability; two of care homes generally; five of nursing homes; two of general community healthcare providers; one of day care services; and one based on a general (consumer) population. The studies were carried out in UK (5), Australia (3), USA (3), Canada (2), Netherlands (2) and Italy (1). The synthesis is structured under three topics sequenced from general principles of using standards in regulation, through implementation to the outcomes of using standards (see Table 2):

- Standards in quality assurance and quality improvement;

- Effectiveness of standards; and

- Design of regulatory standards.

Table 2. Included studies by synthesis headings.

\begin{tabular}{|l|l|l|l|}
\hline Authors, date and country & $\begin{array}{l}\text { Standards in quality } \\
\text { assurance and } \\
\text { quality improvement }\end{array}$ & $\begin{array}{l}\text { Effectiveness } \\
\text { of standards }\end{array}$ & $\begin{array}{l}\text { Design of regulatory } \\
\text { standards }\end{array}$ \\
\hline $\begin{array}{l}\text { Allan \& Forder. 2015 } \\
\text { UK }\end{array}$ & $\checkmark$ & & \\
\hline $\begin{array}{l}\text { Baldwin et al. 2015 } \\
\text { Australia }\end{array}$ & $\checkmark$ & & \\
\hline $\begin{array}{l}\text { Bardsley et al. 2009 } \\
\text { UK }\end{array}$ & $\checkmark$ & $\checkmark$ & \\
\hline $\begin{array}{l}\text { Beadle-Brown et al. 2007 } \\
\text { UK }\end{array}$ & & $\checkmark$ & \\
\hline $\begin{array}{l}\text { Bouwman et al. 2015 } \\
\text { Netherlands }\end{array}$ & & $\checkmark$ & \\
\hline $\begin{array}{l}\text { Bravo et al. 2014 } \\
\text { Canada }\end{array}$ & $\checkmark$ & $\checkmark$ & \\
\hline $\begin{array}{l}\text { Chen \& Grabowski. 2015 } \\
\text { USA }\end{array}$ & & $\checkmark$ & \\
\hline $\begin{array}{l}\text { Choiniere et al. 2016 } \\
\text { Canada }\end{array}$ & & $\checkmark$ & $\checkmark$ \\
\hline $\begin{array}{l}\text { Colon-Emeric et al. 2010 } \\
\text { USA }\end{array}$ & & $\checkmark$ & \\
\hline $\begin{array}{l}\text { Ellis \& Howe. 2010 } \\
\text { Australia }\end{array}$ & & $\checkmark$ & \\
\hline $\begin{array}{l}\text { Gage et al. 2009 } \\
\text { UK }\end{array}$ & & $\checkmark$ & \\
\hline $\begin{array}{l}\text { Kim et al. 2009 } \\
\text { USA }\end{array}$ & & & \\
\hline $\begin{array}{l}\text { O'Dwyer. 2015 } \\
\text { Italy }\end{array}$ & & & \\
\hline $\begin{array}{l}\text { Ostaszkiewicz et al. 2016 } \\
\text { Australia }\end{array}$ & $\checkmark$ & & \\
\hline $\begin{array}{l}\text { Reilly et al. 2006 } \\
\text { UK }\end{array}$ & & & \\
\hline $\begin{array}{l}\text { Stoopendaal et al. 2016 } \\
\text { Netherlands }\end{array}$ & $\checkmark$ & & \\
\hline
\end{tabular}


The language across studies was not entirely consistent, particularly in relation the use of the term "compliance", and where this is located along a continuum from deterrence to improvement.

\section{Standards in quality assurance and quality improvement}

The use of standards may vary along a continuum from a deterrence approach (formal, legalistic, regulatory) to a supportive improvement approach, as in a study (Choiniere et al., 2016) which mapped inspection and audit processes of nursing homes in six countries which were classified as "liberal welfare regimes", "conservative welfare regime", and "social democratic welfare regimes". A case study approach across 27 countries (O'Dwyer, 2015) illustrated how the use of standards extended to self-regulatory approaches by providers in Northern European countries, perhaps reflecting the financial investment in care. Provider selfdeclarations may be used to gauge compliance with standards as evaluated in a study of 44 standards in 567 organisations in England (Bardsley et al., 2009). However, a populationbased survey of 1500 members of the Dutch Healthcare Consumer Panel illustrated a lack of public confidence that providers are able to self-regulate meaningfully (Bouwman et al., 2015). The public may be concerned that the provider's internal monitoring arrangements are not adequate for self-regulation, and that they would not report openly. The public seemed more comfortable with "command and control" and "deterrence" approaches.

Quality improvement approaches were more common in countries with fewer for-profit care homes; the command and control approach was more prevalent where there was growth of for-profit ownership (O'Dwyer, 2015). A study of secondary qualitative data identified factors associated with sanctioned homes where enforcement actions had been taken (Baldwin et al., 2015). Some providers took risks with compliance in order to avoid regulatory scrutiny whilst maintaining profit. An analysis of secondary data (Allan \& Forder, 2015: 134) to test for factors related to home closures in England found that some providers will balance "small risk of regulatory action" with potential profitability.

Achieving quality improvement using a self-governance model relies on the regulator's approach being conducive to enabling providers to achieve - and exceed - standards. Provider self-reporting on standards may be associated with the highest quality of care (O'Dwyer, 2015) although the selection of self-reporting rather than other quality measures may reflect differences in financial investment in services and in culture between countries. However, a qualitative study of system-based regulation and engagement of providers in improvement processes in the Netherlands (Stoopendaal et al., 2016) showed that the provider needed to have appropriate organisational structures, motivation and governance procedures in place, and that inspections should check for evidence of improvement systems. The study found that providers resisted involvement, fearing that the bureaucratic burden of evidencing compliance would divert from improving care.

There are gains in involving providers in the development and creation of regulatory processes, such as greater understanding of the task in hand; enhancing natural development of self-governance processes; and providers informing regulators about the impact of regulatory changes such as when they were ineffective and burdensome (Stoopendaal et al., 2016). Paperwork to evidence self-governance was concerning as a staff burden at the expense of quality care. A mixed methods study in Australia of continence care (involving 88 hours of observation and interviews with 18 staff) (Ostaszkiewicz et al., 2016) found that some staff focussed on evidencing compliance rather than improving outcomes. A self-regulatory approach relies on the provider taking responsibility for compliance and evidencing that they are achieving or exceeding minimum standards. Regulatory control may disempower providers from taking responsibility for quality of care (O'Dwyer, 2015), but whether "self-regulation" promotes better care and outcomes in competitive markets was not clear, in addition to anticipated variation across individuals, organisations and cultures.

\section{Effectiveness of standards}


Standards have a clear role, but their influence depends on how they are used in practice by care staff, provider organisations and regulatory staff. The conclusion drawn in a longitudinal study of over 100 nursing homes in Canada (using data collected prior to and after regulation was introduced) was that the introduction of benchmarking standards improved the quality of care in privately-owned homes, measured using the QUALCARE Scale (Bravo et al., 2014).

A study of secondary data on 138 sanctioned homes in Australia indicated that enforcement action seemed to be more associated with contextual factors such as complaints and staffing arrangements rather than by performance measured against standards (Ellis \& Howe, 2010). "Soft intelligence" such as complaints may be more important in raising the awareness of regulators and providers regarding areas of care requiring improvement (Bouwman et al., 2015).

Staff may emphasise maintaining written evidence of performance (such as care planning documents) over actual care (Ostaszkiewicz et al., 2016) if their focus is on complying with regulation to avoid criticism. In an in-depth multiple-case study in the USA, Colon-Emeric et al. (2010) found that staff may: (1) respond to benchmarks and quality indicators as inflexible and bureaucratic (typically leading to routine and inflexible approaches to care, centred on the regulation or standard); or (2) link standards to the needs of individual service users (leading to some examples of high quality care, where the leadership model promoted thoughtful staff).

A panel data analysis employing a random-effect model in the USA (Kim et al., 2009) found that total staffing level was a predictor of deficiencies, and this has led in some jurisdictions to the development of staffing standards. However, although higher staffing levels generally correlate with better quality care, one panel data analysis of nursing home regulation in the USA (Chen \& Grabowski, 2015) found that some homes with higher staffing levels bought cheaper labour when staffing requirements were broad. If roles, qualifications and responsibilities are not specified, standards regarding staff numbers may not improve care.

\section{Design of regulatory standards}

The way that individual standards are written may influence the outcome of the use of the standard (Ostaszkiewicz et al., 2016). The onus on providers to comply with standards may influence their selection of service users, raising ethical and other issues for service managers. Inspectors' judgements in England were sometimes influenced by how easily they perceived the standard was to assess, and prior knowledge of risk information (Bardsley, et al., 2009).

A study of 258 inspection reports in one county in England (Gage et al., 2009) highlighted the importance of outcomes-based standards. Quality of care, as defined by failures on national standards, was statistically associated with features of care homes and their residents. A higher probability of failing a standard was significantly associated with being a home that: was a for-profit small business (adjusted risk ratio 1.17) or was registered before the year 2000 (adjusted risk ratio 1.22). It was noteworthy that the study found that high achievement in managerial standards correlated with fewer failures in other standards.

The need for standards to capture important service user outcomes and experiences was highlighted in the analysis of qualitative data from 52 care home inspections in England by (Beadle-Brown et al., 2007). The conclusion could be drawn from these two studies that regulators should directly associate standards with the lived experience of service users. In their study of 79 day centres and day hospitals for people with dementia in England, Reilly et al. (2006) highlighted how standards may be created in ways that promote quality outcomes for service users, such as inclusion of standards for assessment and care planning; promotion of rehabilitation; provision of transport; family involvement; and specialist staff training.

\section{Discussion}

A number of studies referred to Donabedian's conceptual model of quality of health care (Ayanian \& Markel, 2016), incorporating the triad of structure, process and outcome. The 
organisational and systems context is important for understanding the effectiveness of standards and how learning and improvement can best be achieved (Bunger et al., 2019).

Community health and social care regulation presents challenges in regulating a diversity of small providers spanning a wide range of services. Regulation is a complex task; the use of standards varies along a continuum from legalistic compliance to supportive selfimprovement approaches. This parallels the debate between quality assurance and quality improvement approaches (Wandersman et al., 2012). Most included studies were of residential and nursing homes for older people. There was only one study of day care services, and none of home care services.

Reviewed studies gave little detail about the standards under consideration, and this was a limitation in comparing and synthesising studies. The way that individual standards are written may affect how well the service is perceived to achieve the standard. For example, standards that focus overly on record-keeping may not attend sufficiently to care as experienced. Inspectors' judgements may be influenced by ease of assessing the standard and prior knowledge of risk information. Enforcement action may be associated with contextual factors such as complaints as much as by inspection against standards. Standards may be more effective where they are based on measurable care outcomes and the lived experiences of service users. Reviewed studies gave little attention to the cognitive processes of inspectors when using standards, despite the importance of ensuring some consistency across inspectors (Ghanem et al., 2019; Taylor, 2012b). There was disappointingly little research on the design of inspection standards, and this is important area for future development. The studies reviewed were informative, but far from conclusive on the effectiveness of standards. Effectiveness and efficiency of inspection will depend on the wording of standards and design of inspection tools, and on their use. Health and social care regulation needs rigorous development of inspection scales rather than relying almost entirely on dichotomous conclusions of "good enough" or not (Munn et al., 2018).

Notably, high scores in managerial standards seemed to correlate with fewer failures in other standards, which may reflect capacity to improve or manage problems (Furnival et al., 2018). There was limited reference to standards capturing the ability of providers to manage risk or improve their own service. Providers need knowledge and skills as well as motivation to self-regulate against standards to improve quality (van der Zwet et al., 2019). Caution needs to be exercised to ensure that standards do not stifle innovative care for patients and service users with complex needs. Despite the value of greater self-regulation, the public tends to favour regulatory approaches (Bouwman et al., 2015).

Developments in the wider world of evidence-based practice (Taylor, 2012c, 2020; Taylor et al., 2017) have potential application in the domain of health and social care regulation. Standards seek to define acceptable care but, as in other aspects of social work, staff attitudes and care environments are important as well as thoughtful methods of work (Fengler \& Taylor, 2019). Inspection using standards is an essential component of quality assurance and quality improvement in health and social care, more rigorous development of effective standards is required.

\section{Conclusion}

The field of social care regulation needs to take cognizance of developments in the wider world of evidence-based practice. Standards seek to define acceptable care, but need appropriate staff attitudes and care environments to be most effective. No tool is perfect; regulation and care will always involve hearts as well as methods.

\section{Acknowledgements}

The authors would like to acknowledge senior managers of the Regulation and Quality Improvement Authority for Northern Ireland for their support amidst operational demands. We would like to thank Mrs Joanne Knox, Assistant Subject Librarian and the teaching team on 
the Research Methods Programme of the MSc Professional Development in Social Work at Ulster University for their inspiration and enthusiasm for getting knowledge into practice.

\section{Declaration of Interests}

The authors declare that there is no conflict of interest.

\section{Funding}

There is no funding to declare.

References (studies included in the review are marked with an asterisk*)

*Allan, S., \& Forder, J. (2015). The determinants of care home closure. Health Economics, 24(Suppl 1), 132-145. https://doi.org/10.1002/hec.3149

Ayanian JZ, Markel H. (2016). Donabedian's lasting framework for health care quality. New England Journal of Medicine, 375, 205-207. https://doi:10.1056/NEJMp1605101

*Baldwin, R., Chenoweth, L., Rama, M., \& Liu, Z. (2015). Quality failures in residential aged care in Australia: The relationship between structural factors and regulation imposed sanctions. Australasian Journal on Ageing, 34, E7-E12. https://doi.org/10.1111/ajag.12165

*Bardsley, M., Spiegelhalter, D. J., Blunt, I., Chitnis, X., Roberts, A., \& Bharania, S. (2009). Using routine intelligence to target inspection of healthcare providers in England. Quality \& Safety in Health Care, 18, 189.

*Beadle-Brown, J., Hutchinson, A., \& Mansell, J. (2007). Care standards in homes for people with intellectual disabilities. Journal of Applied Research in Intellectual Disabilities, 21, 210 218. https://doi.org/10.1111/j.1468-3148.2007.00400.x

Best, P., Taylor, B. J., Manktelow, R., \& McQuilkin, J. (2014). Systematically retrieving research in the digital age: Case study on the topic of social networking sites and young people's mental health. Journal of Information Science, 40: 346-356. https://doi:10.1177/0165551514521936

*Bouwman, R., Bomhoff, M., de Jong, J. D., Robben, P., \& Friele, R. (2015). The public's voice about healthcare quality regulation policies: A population-based survey. BMC Health Services Research, 15, 325. https://doi.org/10.1186/s12913-015-0992-z

${ }^{*}$ Bravo, G., Dubois, M., Demers, L., Dubuc, N., Blanchette, D., Painter, K., Lestage, C., \& Corbin, C. (2014). Does regulating private long-term care facilities lead to better care? A study from Quebec, Canada. International Journal for Quality in Health Care, 26, 330-336. https://doi.org/10.1093/intqhc/mzu032

Brennan, S., McKenzie, J., Whitty, P., Buchan, H., Green, S., Bosch, M., Fiander, M., Strobel, N. A., Donoghue, E., Page, M. J., Yost, J., \& Gonçalves-Bradley, D. C. (2017). Continuous quality improvement: effects on professional practice and healthcare outcomes in primary care. Cochrane Database of Systematic Reviews, 11, CD003319.

Bunger, A. C., Despard, M., Lee, M., \& Cao, Y. (2019). The cost of quality: Organizational financial health and program quality. Journal of Evidence-Based Social Work, 16, 18-35. https://doi:10.1080/23761407.2018.1536575

Campbell, A., Taylor, B. J., Bates, J., \& O'Connor-Bones, U. (2018). Developing and applying a protocol for a systematic review in the social sciences. New Review of Academic Librarianship, 24(1), 1-22. https://doi:10.1080/13614533.2017.1281827

Care and Social Services Inspectorate in Wales. (2016). About us. Cardiff: author.

Care Inspectorate. (2016). What the Care Inspectorate does. Edinburgh: Care Information Scotland.

Care Quality Commission. (2016). What we do. London: author.

Care Quality Commission. (2017). The fundamental standards. London: author.

${ }^{*}$ Chen, M. M., \& Grabowski, D. C. (2015). Intended and unintended consequences of minimum staffing standards for nursing homes. Health Economics, 24, 822-839. https://doi.org/10.1002/hec.3063 
${ }^{*}$ Choiniere, J. A., Doupe, M., Goldman, M., Harrington, C., Jacobson, F. F., Lloyd, L., Rootham, M., \& Szebehely, M. (2016). Mapping nursing home inspections and audits in six countries. Ageing International, 41, 40-61. https://doi.org/10.1007/s12126-015-9230-6

${ }^{*}$ Colon-Emeric, C. S., Plowman, D., Bailey, D., Corazzini, K., Utley-Smith, Q., Ammarell, N., Toles, M., \& Anderson, R. (2010). Regulation and mindful resident care in nursing homes. Qualitative Health Research, 20, 1283-1294. https://doi.org/10.1177/1049732310369337

*Ellis, J. M., \& Howe, A. (2010). The role of sanctions in Australia's residential aged care quality assurance system. International Journal for Quality in Health Care, 22, 452-460. https://doi.org/10.1093/intqhc/mzq055

Fengler, J. \& Taylor, B. J. (2019). Effective assessment: A key knowledge and skill for a sustainable profession. Social Work Education: The International Journal, 38(3), 392-405. https://doi:10.1080/02615479.2018.1538333

Fleming, G. \& Taylor, B.J. (2010). An evaluation of day support: A community rehabilitation service? International Journal of Disability, Community and Rehabilitation, 9. ISSN 17033381. www.ijdcr.ca/VOL09 01/articles/taylor.shtml

Flodgren, G., Pomey, M.-P., Taber, S. A., \& Eccles, M.P. (2011). Effectiveness of external inspection of compliance with standards in improving health care organisation behaviour or patient outcomes. Cochrane Database of Systematic Reviews, 11, CD008992. https://doi: 10.1002/14651858.CD008992.pub2.

Furnival, J., Boaden, R., \& Walshe, K. (2018). Assessing improvement capability in healthcare organisations: A qualitative study of healthcare regulatory agencies in the UK. International Journal for Quality in Health Care, 30, 715-723. https://doi.org/10.1093/intqhc/mzy085

*Gage, H., Knibb, W., Evans, J., Williams, P., Rickman, N., \& Bryan, K. (2009). Why are some care homes better than others? An empirical study of the factors associated with quality of care for older people in residential homes in Surrey, England. Health \& Social Care in the Community, 17, 599-609. https://doi.org/10.1111/j.1365-2524.2009.00861.x

Ghanem, C., Kollar, I., Pankofer, S., Eckl, M., \& Fischer, F. (2019). Does Probation Officers' reasoning change in the light of scientific evidence? Analyzing the quality of evidence utilisation in social work. Journal of Evidence-Based Social Work, 16, 423-441. https://doi:10.1080/26408066.2019.1618774

Harris, B. (Ed.). (2016). Welfare and old age in Europe and North America. Routledge.

Health and Social Care Board. (2012). The social work strategy. Belfast: author.

Health and Social Care Board. (2015). Social work research and continuous improvement strategy 2015-2020. Belfast: author.

Killick, C. \& Taylor, B.J. (2020). Assessment, risk and decision making in social work: An introduction. Sage.

*Kim, H., Kovner, C., Harrington, C., Greene, W., \& Mezey, M. (2009). A panel data analysis of the relationships of nursing home staffing levels and standards to regulatory deficiencies. Journals of Gerontology Series B-Psychological Sciences \& Social Sciences, 64, 269-278. https://doi.org/10.1093/geronb/gbn019

Mc Elhinney, H., Taylor, B. J., Sinclair, M., \& Holman, M. R. (2016). Sensitivity and specificity of electronic databases when searching for evidence on child protection issues related to pregnant women. Evidence Based Midwifery, 14: 29-34. ISSN: 1479-4489

McFadden, P., Taylor, B. J., Campbell, A., \& McQuilkin, J. (2012). Systematically identifying relevant research: case study on child protection social workers' resilience. Research on Social Work Practice, 22, 626-636. https://doi:10.1177/1049731512453209

McGinn, A. H., Taylor, B. J., McColgan, M., \& McQuilkin, J. (2016). Social work literature searching: current issues with databases and online search engines. Research on Social Work Practice, 26, 266-277. https://doi:10.1177/1049731514549423

Munn, J., Radey, M., Brown, K., \& Kim, H. (2018). Revising the Lubben Social Network Scale for use in residential long-term care settings. Journal of Evidence-Informed Social Work, 15, 385-402. https://doi:10.1080/23761407.2018.1460734

*O'Dwyer, C. (2015). But does it work? The role of regulation in improving the quality of residential care for older people in Europe. Quality in Ageing and Older Adults, 16, 118128. ISSN: 1471-7794 
Office of Health Care Quality Maryland. (2019). Code of Maryland regulations. Baltimore, MD: author.

*Ostaszkiewicz, J., O'Connell, B., \& Dunning, T. (2016). Fear and overprotection in Australian residential aged-care facilities: The inadvertent impact of regulation on quality continence care. Australasian Journal on Ageing, 35, 119-126. https://doi.org/10.1111/ajag.12218

Regulation and Quality Improvement Authority. (2016). RQIA provider guidance: Day care settings. Belfast: author.

*Reilly, S., Venables, D., Hughes, J., Challis, D., \& Abendstern, M. (2006). Standards of care in day hospitals and day centres: A comparison of services for older people with dementia. International Journal of Geriatric Psychiatry, 21, 460-468. https://doi.org/10.1002/gps.1495

Resodihardjo, S.L. (2020). Crises, inquiries and the politics of blame. Palgrave Macmillan.

Scheweppenstedde, D., Hinrichs, S., Ogbu, U. C., Schneider, E. C., Kringos, D. S., Klazinga, N. S., Healy, J., Vuorenkoski, L., Busse, R., Guerin, B., Pitchforth, E., \& Nolte, E. (2014). Regulating Quality and Safety of Health and Social Care: International Experiences. Cambridge: Rand.

Simmons, L., Huddleston-Casas, C. A., Morgan, K. A., \& Feldman, D. (2012). Mixed methods study of management of health conditions in rural low-income families: implications for health care policy in the USA. Rural and Remote Health, 12: 1879. http://www.rrh.org.au/journal/article/1879

Stevenson, M., Taylor, B. J., \& Knox, J. (2016). Risk in dementia care: Searching for the evidence. Health, Risk and Society, 18, 4-20. https://doi:10.1080/13698575.2015.1119256

*Stoopendaal, A., De Bree, M., \& Robben, P. (2016). Reconceptualizing regulation: Formative evaluation of an experiment with system-based regulation in Dutch healthcare. Evaluation, 22, 394-409. https://doi.org/10.1177/1356389016667889

Taylor, B. J. (1998). Service needs and individual qualifications: Training Social Workers for the community care policy initiative and post-qualifying credits. Social Work Education, 17, 77-93.

Taylor, B. J. (1999). Developing partnership between professions in implementing new children's legislation in Northern Ireland. Journal of Inter-Professional Care, 13, 249-259.

Taylor, B. J. (2006). Risk management paradigms in health and social services for professional decision making on the long-term care of older people. British Journal of Social Work, 36, 1411-1429. https://doi:10.1093/bjsw/bch406

Taylor, B. J. (2012a). Developing an integrated assessment tool for the health and social care of older people. British Journal of Social Work, 42, 1293-1314. https://doi:10.1093/bjsw/bcr133

Taylor BJ (2012b) Models for professional judgement in social work. European Journal of Social Work, 15(4), 546-562. https://doi.10.1080/13691457.2012.702310

Taylor, B. J. (2012c). Intervention research. In M. Gray, J. Midgley \& S. Webb (Eds.), The SAGE handbook of social work. Sage.

Taylor, B. J. (2017a). Heuristics in professional judgement: A psycho-social rationality model. British Journal of Social Work, 47, 1043-1060. https://doi:10.1093/bjsw/bcw084

Taylor, B. J. (2017b). Decision making, assessment and risk in social work ( $3^{\text {rd }}$ ed). Sage.

Taylor, B.J. (2020). Using research in social work. In Parker, J. (Ed.). Introducing social work. (Chapter 14; pp. 160-171). Sage.

Taylor, B. J. \& Campbell, B. (2011). Quality, risk and governance: Social Workers' perspectives. International Journal of Public Leadership, 7, 256-272. https://doi:10.1108/17479881111194152

Taylor, B. J., Dempster, M., \& Donnelly, M. (2003). Hidden gems: Systematically searching electronic databases for research publications for social work and social care. British Journal of Social Work, 33, 423-439. https://doi:10.1093/bjsw/33.4.423

Taylor, B. J. \& Donnelly, M. (2006). Risks to home care workers: Professional perspectives. Health, Risk \& Society, 8, 239-256. https://doi:10.1080/13698570600871695

Taylor, B. J., Killick, C., Bertotti, T., Enosh, G., Gautschi, J., Hietamäki, J., Sicora, A., \& Whittaker, A. (2017). European Social Work Research Association SIG to study decisions, 
assessment and risk. Journal of Evidence-Informed Social Work, 15(1), 82-94. https://doi:10.1080/23761407.2017.1394244

Taylor, B. J., Killick, C., \& McGlade, A. (2015). Understanding and using research in social work. Sage.

Taylor, B.J. \& Moorhead, A. (2020). The social sciences. In P. Bahri (Ed.). Communicating about risks and safe use of medicines: Real life and applied research. (Chapter 8). Springer.

Taylor, B. J., Wylie, E., Dempster, M., \& Donnelly, M. (2007). Systematically retrieving research: a case study evaluating seven databases. Research on Social Work Practice, 17(6), 697-706. https://doi:10.1177/1049731507304402

van der Zwet, R.J.M., Beneken genaamd Kolmer, D.M., Schalk, R., \& Van Regenmortel, T. (2019). Views and attitudes towards evidence-based practice in a Dutch social work organization. Journal of Evidence-Based Social Work, 16, 245260. https://doi:10.1080/23761407.2019.1584071

Wandersman, A., Chien, V.H., \& Katz, J. (2012). Toward an evidence-based system for innovation support for implementing innovations with quality: Tools, training, technical assistance, and quality assurance/quality improvement. American Journal of Community Psychology, 50(4), 445-459. 